\title{
Report from the Editor in Chief, year 2015
}

\author{
Michela Milano ${ }^{1}$
}

Published online: 20 May 2016

(C) Springer Science+Business Media New York 2016

I started my term as Editor in Chief of the Constraint Journal on the 1st of January 2015. The purpose of this short report is to provide some news about the journal to the Editorial and Advisory board members and to the constraint programming community.

\section{Editors, advisory and editorial board members}

Some members of the Editorial Board whose term finished at the end of 2014 and 2015 have been replaced by the following members:

- David Cohen, University of London, UK

- Alan Frisch, University of York, UK

- Michele Lombardi, Università di Bologna, Italy

- Bart Selman, Cornell University, USA

- Makoto Yokoo, Kyushu University, Japan

- Christine Solnon, INSA de Lyon, France

- Toby Walsh, NICTA and UNSW, Australia

- Laurent Michel, University of Connecticut, USA

- David Bergman, University of Connecticut, USA

The previous Editor in Chief, Gilles Pesant has been nominated as a member of the Advisory Board.

The Constraints journal has also four Editors

- APPLICATIONS EDITOR

- Pascal Van Hentenryck, The University of Michigan, USA

\section{Michela Milano}

michela.milano@unibo.it

1 DISI - Università di Bologna, Viale Risorgimento, 2, 40136, Bologna, Italy 
- $\quad$ LETTERS EDITOR

- Christian Schulte, Royal Institute of Technology, Sweden

- $\quad$ SURVEYS EDITOR

- Louis Martin Rousseau, Polytechnique Montréal, Canada

- MEDIA EDITOR

- Pierre Schaus, UC Louvain, Belgium

The media editor is a new position that helps in advertising the journal inside and outside the constraint community.

Two previous editors, ending their term in 2015 are Helmut Simonis for the application side and Thomas Schiex for the surveys. I would like to thank them for their invaluable help with the journal.

\section{Journal advertising}

The advertising of the journal relies on social networks (Constraints is now on Twitter, please follow us!!! @ cp_constraints). In addition, we will have video abstracts linked to each paper. Video abstracts are short presentations summarising the content of the paper.

\section{Review time}

In the following table, the journal turnaround time is reported for year 2015. Notice that the average number of days for a first decision is around one month which is an extremely good figure.

\begin{tabular}{llc}
\hline Submission to Editor Assignment & $\begin{array}{l}\text { Average number of days between } \\
\text { the date the manuscript was received } \\
\text { and the first Editor was assigned: }\end{array}$ & 0.7 \\
Submission to Reviewer Invitation & $\begin{array}{l}\text { Average number of days between } \\
\text { the date the manuscript was received } \\
\text { and the first Reviewer was invited: } \\
\text { Average number of days between } \\
\text { the date the manuscript was received } \\
\text { and the first decision: }\end{array}$ & \multirow{2}{*}{$\begin{array}{l}33.8 \\
\end{array}$} \\
\hline
\end{tabular}

\section{$4 \mathrm{PhD}$ thesis abstract}

The main aim of this initiative is to highlight recent work by $\mathrm{PhD}$ students in the area of Constraints.

Therefore, in conjunction with the $\mathrm{PhD}$ Thesis Archive, the Constraints Journal publishes one page abstracts of $\mathrm{PhD}$ thesis. In 2015 we collected 22 abstracts from students who graduated in 2012-2015. The next years we expect a lower number of abstracts as we will cover only one year. $\mathrm{PhD}$ abstracts will not be indexed as far as citations are concerned. Guido Tack and Christopher Mears are the guest editors of this initiative. 


\section{Fast track journal papers at $\mathrm{CP}$ and CPAIOR}

Program Chairs of CP and CPAIOR are invited to select a set of papers to be directly submitted to the Journal fast track with a one page abstract in the conference proceedings.

The process is as follows:

- The best regular submissions to the conference are selected by the Program Chair

- Authors are invited to extend the paper and submit it to the Constraints Journal addressing all comments from reviewers

- If they accept we ensure one or two very fast round of review

- Papers are published on line at the conference starting day

- Stay open access for 20 days, accessible to everyone.

- One page abstract appears in the conference proceedings, but not indexed as citations are concerned.

In 2015 both CPAIOR and CP chairs have chosen this formula, and also in 2016 the program chair have agreed to have fast track papers.

\section{Concluding remarks}

As a concluding remark, I would like to thank all editors, members of the advisory and editorial board and all the reviewers for their invaluable help with the journal. A special thank goes to Gilles Pesant, the previous Editor in Chief of Constraints and to Melissa Fearon, Springer for their help and support in running the journal.

Michela Milano, Editor-in-Chief 